\title{
EM BUSCA DO CONHECIMENTO CONFIÁVEL: REFLEXÃO À LUZ DO PENSAMENTO DE JOHN ZIMAN
}

Elizabeth Teixeira ${ }^{1}$, Horácio Pires Medeiros ${ }^{2}$

\begin{abstract}
RESUMO: Estudo de reflexão, apoiado na análise de conteúdo, que teve por objetivo ampliar a discussão entre pesquisadores de Enfermagem sobre os desafios da produção científica, para atingir grau equivalente ou próximo ao do conhecimento confiável, à luz do pensamento de John Ziman. O grau de conhecimento confiável passa pela obtenção do consenso entre os pares, a organicidade da produção e o agir comunicativo, entre outros aspectos. Os desafios aos pesquisadores se configuram não só como teórico-metodológicos, mas epistemológicos e sociais. Sugere-se estar atento aos limites (e ausências) e possibilidades (perspectivas emergentes), a fim de fortalecer e contribuir com o conhecimento produzido, disseminado e em expansão na Enfermagem brasileira. PALAVRAS-CHAVE: Ciência; Conhecimento; Pesquisa em enfermagem.

\section{IN SEARCH OF RELIABLE KNOWLEDGE: REFLECTION IN THE LIGHT OF THE THINKING OF JOHN ZIMAN}

\begin{abstract}
A reflective study, based on content analysis, which aimed to widen discussion among Nursing researchers on the subject of the challenges of scientific literature production, to attain a degree of knowledge which is reliable or nearly so, in the light of the thinking of John Ziman. The degree of knowledge's reliability passes through the obtaining of consensus between pairs, the organicity of production and the communicative act, among other aspects. The challenges to researchers are not only theoretical-methodological, but also epistemological and social. It is suggested to be attentive to limits (and absences) and possibilities (emerging perspectives), in order to strengthen and contribute to the knowledge produced, disseminated and in expansion in Brazilian Nursing.

KEYWORDS: Science; Knowledge; Nursing Research.

\section{EN BÚSQUEDA DEL CONOCIMIENTO CONFIABLE: REFLEXIÓN A LA LUZ DEL PENSAMIENTO DE JOHN ZIMAN}

RESUMEN: Estudio de reflexión, apoyado en el análisis de contenido, que tuvo por objetivo ampliar la discusión entre investigadores de Enfermería sobre los desafíos de la producción científica, para atingir grado equivalente o próximo al del conocimiento confiable, a la luz del pensamiento de John Ziman. El grado de conocimiento confiable pasa pela obtención del consenso entre las parejas, la organicidad de la producción y el actuar comunicativo, entre otros aspectos. Los desafíos a los investigadores se configuran no sólo como teórico-metodológicos, pero epistemológicos y sociales. Se sugiere estar atento a los límites (y ausencias) y posibilidades (perspectivas emergentes), a fin de fortalecer y contribuir con el conocimiento producido, diseminado y en expansión en la Enfermería brasileña.

PALABRAS CLAVE: Ciencia; Conocimiento; Investigación en enfermería.

'Enfermeira. Doutora em Ciências. Professora do Departamento de Enfermagem da Universidade do Estado do Pará e do Programa de Mestrado Associado de Enfermagem Universidade do Estado do Pará e Universidade Federal do Amazonas . Líder do Grupo de Pesquisa Práticas Educativas em Saúde e Cuidado na Amazônia - PESCA.

${ }^{2}$ Acadêmico do Curso de Graduação em Enfermagem da Universidade do Estado do Pará. Membro do PESCA.

Autor correspondente:

Elizabeth Teixeira

Universidade do Estado do Pará

R. Municipalidade, 949/Júpiter/1104 - 66050-350 - Belém-PA-Brasil

E-mail: etfelipe@terra.com.br

Recebido: $19 / 09 / 10$

Aprovado: 29/03/11 


\section{INTRODUÇÃO}

Estudos sinalizam as contribuições da Associação Brasileira de Enfermagem, com ênfase no Centro de Estudos e Pesquisas em Enfermagem, para o fortalecimento e disseminação das pesquisas da área ${ }^{(1-3)}$. Mais recentemente, com a constituição da Biblioteca Virtual de Saúde-Enfermagem, a partir de 2007, começa uma ampla publicização do conhecimento produzido pelos pesquisadores de Enfermagem. Muitos outros aspectos poderiam ser aqui ressaltados sobre a pesquisa em Enfermagem no Brasil, mas o que desejamos é chamar a atenção para as travessias que a Enfermagem tem e vem fazendo enquanto área de pesquisa e campo (fértil e em construção) de conhecimento. Este dado nos suscita e nos instiga a promover uma reflexão sobre a construção científica, que contribua com o conhecimento produzido, disseminado e em expansão na Enfermagem brasileira.

As dificuldades com pesquisa, destacadas ${ }^{(4-6)} \mathrm{e}$ relacionadas a aspectos epistemológicos, devem ser discutidas no âmbito da graduação e pós-graduação, e os desafios da construção científica enfrentados, especificamente, pelos pesquisadores da área de Enfermagem. Ao enfrentar nossas precariedades, nos fortalecemos para dominar nossas dificuldades. Nesse sentido, as limitações dos resultados das pesquisas nos impulsionam a enfrentar o desafio das evidências sobre a prática e, sobretudo, do status de um conhecimento confiável ${ }^{(6)}$.

O objetivo desta reflexão é, pois, contribuir com a discussão acerca do conhecimento confiável, aqui tomado como um dos desafios para os pesquisadores de Enfermagem, o que será feito à luz do pensamento de John Ziman (1925-2005), filósofo que da Física Teórica deslocou seus interesses para a Filosofia da Ciência. Suas discussões mais contemporâneas versaram sobre a responsabilidade social dos cientistas, conhecimento público e conhecimento confiável. Para tanto, tomamos a obra do autor ${ }^{(7)}$ como fonte primária (e principal) e, após submetê-la à análise de conteúdo categorial-temática (pré-análise; exploração do material ou codificação; tratamento dos resultados, inferência e interpretação), identificamos dez unidades emergentes do texto. Outras tantas unidades poderiam ser listadas (o convite está feito); as aqui apresentadas são, a nosso ver, aquelas que podem, num primeiro momento, subsidiar reflexões sobre a produção científica e os desafios do conhecimento confiável entre os pesquisadores de Enfermagem.

\section{O CONHECIMENTO CONFIÁVEL NA PERS- PECTIVA DE JOHN ZIMAN: UNIDADES TE- MÁTICAS}

A primeira unidade temática que se destaca é "Consensibilidade \& consensualidade". Para o autor a meta da ciência é buscar a consensualidade. Esta "é uma condição necessária para qualquer comunicação científica"(7:18). Uma afirmação ou tese consensual é aquela plenamente testada e objeto de um acordo universal em torno dela. O primeiro momento a se atingir é a consensibilidade que deve levar à consensualidade, a pedra de toque da confiabilidade da ciência, segundo o autor. A consensibilidade é obtida nos grupos sociais a que pertencemos e dos quais extraímos nosso sustento como seres pensantes. A partir daí, vai-se em busca do consenso universal.

Para o autor, "o que garante a objetividade do mundo em que vivemos é o que temos em comum com outros seres pensantes" ${ }^{\text {"(7:21) }}$, e assim, toda estratégia da ciência está concentrada na criação de um máximo consenso, que é um dos desafios dos pesquisadores. Os professores e as fontes (livros, revistas científicas) revelam o consenso corrente em torno de um tema, e a eles devemos recorrer para o identificar. O pesquisador poderá realizar uma avaliação do peso consensual de vários pontos de vista em torno de um tema: "o melhor que podemos esperar é uma resposta classificada como a opinião quase unânime dos especialistas, apoiada pelo que seria descrito como o peso esmagador das provas" $"(7: 24)$.

A segunda unidade é "Desdogmatismo \& multiplicidade do conhecimento". O desdogmatismo refere-se à não-aceitação da ideia de que só há uma linguagem (a matemática) a ser usada na produção do conhecimento na ciência. Refere o autor que "o uso da linguagem matemática é uma característica desejável, mas não essencial, de um ramo da ciência"(7:92). Há que se ter mensagens significativas na ciência, e as linguagens deverão ser as mais adequadas para que sejam trocadas entre os cientistas. Tal utilização (da linguagem matemática) não gera, automaticamente, um conhecimento confiável.

O desdogmatismo também se refere à certeza, pois há que se acatar as incertezas: "Temos que aceitar o que a natureza nos oferece, torrentes desordenadas de átomos em configurações geométricas imperfeitas, com as limitações da detecção"(7:92). Assim pensando, o que esperar da natureza humana? O que se buscar então? Segundo o autor, é necessário buscar padrões 
que possam ser aceitos, reconhecidos e assimilados intelectualmente sem ser necessária uma definição e análise completas em linguagem matemática ou lógica formal. Formas erráticas e difusas também poderão ser aceitas, neste contexto: "[...] até as ciências concretas são falíveis"(7:92). Assim, a ciência dependerá dos poderes humanos de percepção, reconhecimento, discriminação e interpretação dos cientistas.

A terceira unidade é "Agir comunicativo \& investigativo". Para o autor, como a ciência é mais do que o conhecimento que os pesquisadores produzem, ela só poderá consistir do que puder ser comunicado, e assim, cabe aos pesquisadores, além da produção, a comunicação do saber produzido. $\mathrm{O}$ agir comunicativo, imprescindível à ciência, permitirá que os cientistas convençam seus leitores ou seu público. Os veículos comunicativos são inúmeros (eventos, livros, revistas) onde os relatórios das pesquisas serão comunicados à comunidade científica.

A comunicação dos pesquisadores, alerta o autor, "nunca deve ser uma afirmativa categórica, deve sempre transmitir a avaliação que o autor faz da credibilidade de suas próprias alegações" ${ }^{\text {" }(778)}$. A força da credibilidade estará diretamente relacionada à intensidade das redes e relações sociais estabelecidas pelo pesquisador, entre seus pares. Tal comunicação deve ter o mesmo rigor dedicado à obtenção de resultados. $\mathrm{O}$ agir comunicativo estará, então, diretamente imbricado ao agir investigativo.

A quarta unidade temática é "Dos resultados \& conclusões". O autor interroga: "quem poderia interessarse pelo que já é conhecido como fato?"(7: 121). A partir dessa questão, há que se pensar que o cientista precisará obter resultados novos, diferentes, e suas experiências não poderão ser meras repetições de triunfos passados. O resultado científico deverá ser, segundo o autor, publicável, com plausibilidade adequada. Os dados brutos obtidos pelos cientistas precisam ser refinados, processados, analisados e também interpretados antes de se tornarem compactos e interessantes, para aí, sim, serem repassados adiante.

Segundo o autor, "o conhecimento científico é confiável na medida em que essa confiança for justificável [...] e nos proporcionar conselhos ponderados e prudentes"(7:122). Assim, os resultados e conclusões precisam nos proporcionar tais conselhos. Precisase de conclusões firmes. Os resultados e conclusões precisarão de um tempo para serem processados pela comunidade científica; enquanto isso, eles não poderão ser nem ignorados nem tomados como base para a ação, ficando, assim, "fora das dimensões da crença e da dúvida científicas"(7:123).

O que se espera de uma ciência é um corpo de conhecimentos, um guia para a ação, significativo, confiável, amplo e profundo em seu alcance. Por essa razão, há que se ter, na Enfermagem, algumas questões em permanente destaque: "qual é o impacto real dos conhecimentos que estamos produzindo, socializando e utilizando na prática do cuidado em enfermagem e saúde? Estes conhecimentos são utilizados por outros profissionais e cidadãos? A formação dos pesquisadores para a pesquisa inclui o compromisso com o impacto na aptidão para pesquisar e socializar os conhecimentos que produz?" (8:170).

A quinta unidade é "Dos cientistas \& suas funções". Uma das principais funções destacadas pelo autor são a comunicação e avaliação pública do que se produz com as pesquisas. Como o conhecimento científico é feito por pessoas e para pessoas, o conteúdo e a qualidade dependerá das funções que os cientistas precisam operar como observadores, comunicadores, assessores e assimiladores, crentes e especialistas abalizados. Para o autor, "o melhor que podemos fazer [...] é ser eternamente críticos, eternamente vigilantes, eternamente céticos"(7:68). O especialista científico precisa ter autoridade intelectual. O cientista tem, assim, uma autoridade especializada que não poderá ser contestada com facilidade por qualquer um.

A sexta unidade é "Sobre a metáfora dos mapas". $\mathrm{O}$ autor refere-se ao mapa como algo multiplamente conectado, em que o conjunto é muito mais forte do que qualquer parte ou elemento isolado. O mapa não poderá ser alterado em um ponto sem que não ocorram repercussões em outros pontos. Assim, analogamente, o conhecimento científico acaba sendo uma teia ou rede de leis, modelos, teorias, fórmulas, hipóteses, e interpretações, tão entrelaçados quanto os elementos dos mapas.

A ideia de mapa leva à ideia de rede, e "quando toda a rede de conhecimento ficar mais apertada, quando mais nos forem dados nas pontas soltas, a interpretação provisória original validar-se-á por si mesma, em virtude da coerência da teoria"(7:49). Fazer um mapa é selecionar e dispor dados segundo um princípio organizador, um esquema conceitual, um paradigma, uma teoria, etc., que dará organicidade ao todo produzido. "Nossos mapas e quadros científicos só podem ser feitos de elementos selecionados e filtrados pela peneira temática"(7:49).

A sétima unidade é "Bases $\&$ centros de pesquisa". Para o autor, as áreas científicas precisam manter 
e preservar um centro de conhecimento, uma base que seja confiável e na qual seja possível se apoiar. O que vai importar para as áreas científicas é o status epistemológico da informação que estiver nos arquivos científicos de tais centros e bases. Há que se ter uma plataforma oficial para expor opiniões.

A oitava unidade é "Das travessias \& riscos dos cientistas". Sobre esse aspecto, o autor destaca que é importante atentar para o que ocorre quando atravessamos da biologia, por exemplo, para as ciências do comportamento e as ciências sociais. Para ele, há uma mudança, pois a lógica de dois valores que se atribui a categorias idealizadas comete uma "injustiça tão grande com suas propriedades e comportamentos inerentes que transforma em disparate a comunicação simbólica, lógica e matemática acerca delas"(7:91). Assim, há que se ter cuidado ao se efetivar tais travessias, pois não há como transpor indiscriminadamente, para outros campos, os mesmos princípios e meios.

A nona unidade é "Conhecimento científico \& senso comum". O autor refere que as evidências do senso comum até podem ser ambíguas, irrelevantes em alguns contextos, mas nunca podem ser simplesmente ignoradas. Referindo-se a Popper, que afirmou que toda a ciência e toda a filosofia são o senso comum esclarecido, completa afirmando que "devemos admitir que algumas formas de senso não são assim tão comuns e que algumas pessoas são muito mais esclarecidas do que outras" (7:32).

A décima e última unidade é "Uma ciência para além das naturais?". Com essa questão provocadora, o autor começa a concluir sua obra destacando o conhecimento social, o cientista social e o senso comum social que, ao seu modo de ver, "é um guia muito satisfatório para a ação social: Todo mundo, de certo modo, é um cientista social bastante competente e não devemos tratar com desprezo a teoria dessa pessoa sobre o mundo social e o lugar dela nesse mundo"(7:133).

\section{CONCLUSÕES}

Constata-se o necessário reconhecimento do status científico tanto das ciências naturais como das ciências do comportamento e sociais, o que indica uma flexibilidade saudável na perspectiva de uma ciência inclusiva e justa, epistemologicamente, com todas as formas de conhecimento, todos os diferentes sensos não tão comuns. $\mathrm{O}$ autor destaca a necessidade de produção de um conhecimento socialmente coerente, o que aproximará o cientista do social.
Conclui-se que os desafios aos pesquisadores em busca da autoridade intelectual relacionam-se não só a aspectos teórico-metodológicos, mas epistemológicos e sociais. O máximo de consenso será obtido entre os pares se houver eficaz comunicação-publicização dos achados, e a confiança está cada vez mais relacionada à organicidade da produção, bem como ao seu compromisso social. Convidamos à leitura da obra como um todo, e quem sabe (por que não?), a sua tessitura com outras tantas (e diferentes) unidades temáticas.

\section{REFERÊNCIAS}

1. Boemer MR, Rocha SMM. A pesquisa em enfermagem: notas de ordem histórica e metodológica. Saúde Soc. 1996;5(1):77-88.

2. Cunha ICKO. O CEPEn e a produção e difusão do conhecimento da enfermagem brasileira. Rev Bras Enferm. 2005;58(1):5-7.

3. Leite JL, Ximenes N, Guimarães FR, Cunha ICKO. Centro de Estudos e Pesquisa em Enfermagem (CEPEn): uma trajetória de 36 anos. Rev Bras Enferm. 2007;60(6):621-6.

4. Carvalho V. Sobre conhecimento geral e específico: destaques substantivos e adjetivos para uma epistemologia da enfermagem. Esc Anna Nery. 2007;11(2):337-42.

5. Carvalho V. Enfermagem e história da enfermagem: aspectos epistemológicos destacados na construção do conhecimento profissional. Esc Anna Nery. 2007;11(3):500-8.

6. Carvalho V. Sobre a objetividade na relação sujeitoobjeto no plano da imagem ou da esfera instrumental/ organizacional: um ponto de vista para a pesquisa na enfermagem. Esc Anna Nery. 2008;12(2):334-40.

7. Ziman J. O conhecimento confiável. Campinas: Papirus; 1996.

8. Lunardi VL, Lunardi Filho WD, Silveira RS, Erdmann AL, Rogrigues, RP, Dalmolin GL. Impacto dos resultados das pesquisas em enfermagem na prática profissional. Cogitare Enferm. 2009;14(1):165-71. 